\title{
In silico identification and characterization of putative differentially expressed genes involved in common bean (Phaseolus vulgaris L.) seed development
}

\author{
Ghassen Abid • Yordan Muhovski • \\ Jean-Marie Jacquemin • Dominique Mingeot • \\ Khaled Sassi · André Toussaint · Jean-Pierre Baudoin
}

Received: 3 February 2011/ Accepted: 3 May 2011

(C) Springer Science+Business Media B.V. 2011

\begin{abstract}
Two genotypes of common bean (Phaseolus vulgaris $\mathrm{L}$.) were studied to determine the structural cause of seed abortion in this species. In the non-abortive control (wild-type, cultivar BAT93), the histological analysis revealed a classical pattern of seed development and showed coordinated differentiation of the embryo proper, suspensor, endosperm tissue and seed coat. In contrast, the ethyl methanesulfonate (EMS) mutant (cultivar BAT93) showed disruption in the normal seed development leading to embryo abortion. Aborted embryos from these degenerate seeds showed abnormalities in suspensor and cotyledons at the globular, heart, torpedo and cotyledon stages. Exploring the feasibility of incorporating the available online bioinformatics databases, we identified 22 genes revealing high homology with genes involved in Arabidopsis thaliana embryo development and expressed in common bean immature seeds. The expression patterns of these genes were confirmed by RT-PCR. All genes were highly expressed in seed tissues. To study the expression profiles of isolated genes during Phaseolus embryogenesis,
\end{abstract}

G. Abid $(\bowtie) \cdot$ A. Toussaint $\cdot$ J.-P. Baudoin

University of Liège-Gembloux Agro-Bio Tech, Unit of Tropical Crop Husbandry and Horticulture, Gembloux Agricultural University, Passage des Déportés 2, 5030 Gembloux, Belgium e-mail: gha_abid@yahoo.fr

G. Abid · Y. Muhovski - J.-M. Jacquemin - D. Mingeot Department of Life Sciences, Unit of Breeding and Biodiversity, Walloon Agricultural Research Centre, Chaussée de Charleroi, 234, 5030 Gembloux, Belgium

\section{K. Sassi}

Department of Agronomy and Plant Biotechnology, Laboratory of Agronomy, University of Carthage, National Agronomy Institute of Tunisia (INAT), Avenue Charles Nicolle, 43, 1082 Tunis-Mahrajène, Tunisia six selected genes were examined by quantitative RT-PCR analysis on the developing embryos of wild-type and EMS mutant plants. All selected genes were expressed differentially at different stages of embryo development. These results could help to improve understanding of the mechanism of common bean embryogenesis.

Keywords EMS mutant - ESTs - Phaseolus vulgaris . RT-PCR $\cdot$ Seed development
Abbreviations
DAP Days after pollination
EMS Ethyl methanesulfonate
EST Expressed sequence tag
RT-PCR Reverse transcription polymerase chain reaction

\section{Introduction}

Embryogenesis plays a central role in the life cycle of flowering plants. Early stages of plant embryo development are characterized by cell division and morphogenesis. After a double fertilization event, egg and sperm nuclei fuse to form the embryo. A second sperm nucleus fuses with the central cell nucleus, initiating the endosperm that supports embryo development (Jürgens 2003). A vast number of genes, such as homeobox genes, heat shock protein genes and lipid transfer protein genes that play a significant role in zygotic embryo development have been identified (Laux et al. 2004). Unquestionably, until now several other genes transcribed during the early and late stages of embryo development have not been identified or examined at the molecular level. Genetics tools provide an interesting approach to the study of plant embryo development by 
enabling genes with essential functions at this critical stage of the life cycle to be identified (Errampalli et al. 1991). Recent studies have focused on embryo mutants whose embryo development had stopped prior to the completion of the body pattern in order to determine the functional characteristics and the expression of genes that are essential for plant embryogenesis (Naway et al. 2008; Baster et al. 2009; Wu et al. 2009).

Expressed sequence tag (EST) analyses have been used extensively to discover novel genes and have proved to be a powerful and rapid way of identifying new genes that are preferentially expressed in embryo tissue during embryogenesis in plants such as Brassica napus (Tsuwamato and Takhata 2008), Helianthus annuus (Ben et al. 2005) and Pinus radiata (Bishop-Hurley et al. 2003). Differential gene expression, such as microarray technique, is a commonly used approach for interpreting gene expression profiles during plant and seed development (Dong et al. 2004; Liu et al. 2010; Zakizadeh et al. 2010).

Ramirez et al. (2005) showed that comparative analysis of common bean genomes with leguminous or non-leguminous species, such as Arabidopsis thaliana and rice (Oryza sativa), provides a valuable tool for in silico analysis of root nodule gene expression.

Genetic analyses have identified Arabidopsis genes that play essential roles during embryogenesis. Several mutations that affect the early stages of embryogenesis correspond to genes involved in the morphogenetic process that occurs during embryo development (Yamagishi et al. 2005). Genetic strategies used to identify regulators of plant embryo development, such as in the plant model Arabidopsis thaliana, therefore help to distinguish the gene classes that affect embryogenesis.

Over 2000 Arabidopsis mutants affected in different events during embryogenesis have been isolated by mutagenesis with ethyl methanesulfonate (EMS), by inserting T-DNA or by transposon tagging (Meinke and Sussex 1979; Jürgens et al. 1994; Kyjovska et al. 2003). Defective embryos represent the largest group of mutants examined in Arabidopsis. Many of these mutants have been described and characterized in some detail (Vidaure et al. 2007; Chandler 2008). Two complementary strategies, based on the phenotypic screening of immature siliques and germinating seedlings, were used to isolate mutants altered in the early phase of embryogenesis. Based on data from these two approaches, various estimates of the number of genes essential to seed development were made. Meinke and Sussex (1979) estimated the number of genes expressed in Arabidopsis embryogenesis to be about 500, whereas Jürgens et al. (1994) believed that 4,000 genes were essential for normal development of the embryo, from which about
40 genes were responsible for the establishment of the embryo morphological pattern.

Tzafrir et al. (2004) used both forward and reverse genetics as novel strategies to identify an initial dataset of 250 embryo genes required for normal embryo development in Arabidopsis.

The goal of this study was to explore the feasibility of incorporating the available online bioinformatic databases to discover common bean genes associated with regulatory and biological response pathways common to both embryogenesis and seed development. We focus here on 22 ESTs from common bean showing the highest homology to 22 known genes required for embryo development in Arabidopsis thaliana (Table 1). Disruption of all the genes selected could affect pattern embryo formation and then lead to embryo abortion in Arabidopsis thaliana (Tzafrir et al. 2004).

We describe the global analysis of the expression of these 22 candidate genes during common bean seed and plant development using semi-quantitative PCR. A comparative analysis of the expression of six selected genes using quantitative PCR in wild-type and EMS mutant plants defective in seed development was performed in order to highlight the putative role of these genes in common bean seed development.

\section{Materials and methods}

\section{Plant materials}

The common bean wild-type and EMS mutant plants were derived from genotype BAT93 of Phaseolus vulgaris. Seeds of BAT93 were mutagenized with EMS (Silué et al. 2006); M1 plants were obtained and the seeds were harvested and grown (M2 plants). From the M1 material, one mutant plant (identified 522) was selected and analysed further. Thirty three M2 seeds from M1 plant (522) were collected individually, grown and selfed; the seeds from M2 plants were collected. Among these 33 putative mutants, 24 were identified as heritable mutants: seven were homozygote (producing defective seeds), and 17 were heterozygote (producing an intermediate phenotype). The nine remaining putative mutants were not inherited (siblings were wild-type).

Seeds from the wild-type and EMS mutant were surfacesterilized in $10 \%$ sodium hypochlorite solution for $10 \mathrm{~min}$, and germinated on moist sterile filter paper. Four-day-old seedlings were transferred to sterilized compost in individual pots and placed in growth chambers supplied with artificial light at $580 \mu \mathrm{E} \mathrm{m}^{-2} \mathrm{~s}^{-1}$ light intensity, $27^{\circ} \mathrm{C} / 23^{\circ} \mathrm{C}$ 
Table 1 Phaseolus vulgaris ESTs showing homology with Arabidopsis thaliana genes required for normal embryo development

\begin{tabular}{|c|c|c|c|c|c|}
\hline $\begin{array}{l}\text { Arabidopsis } \\
\text { thaliana } \\
\text { accession } \\
\text { number }\end{array}$ & Name & Putative function & $\begin{array}{l}\text { Phaseolus } \\
\text { vulgaris EST } \\
\text { accession number }\end{array}$ & $\begin{array}{l}\text { Nucleic acid } \\
\text { identity }\end{array}$ & E-value \\
\hline At4g02980 & ABP1 & $\begin{array}{l}\text { Auxin binding protein involved in cell elongation and cell } \\
\text { division }\end{array}$ & CV529696 & (373/499) $74 \%$ & $2.00 \mathrm{E}-92$ \\
\hline At3g11940 & AML1 & Encodes ribosomal protein S5 & EY457929 & (401/485) $82 \%$ & $2.00 \mathrm{E}-74$ \\
\hline At3g60830 & ARP7 & Encodes an actin-related protein & FE711613 & (274/351) $79 \%$ & $5.00 \mathrm{E}-81$ \\
\hline At4g02570 & AXR6 & $\begin{array}{l}\text { Component of SCF ubiquitin ligase complexes involved in } \\
\text { mediating responses to auxin }\end{array}$ & FE695779 & $(530 / 670) 78 \%$ & $5.00 \mathrm{E}-56$ \\
\hline At2g43360 & $\mathrm{BIO} 2$ & Catalyzes the conversion of dethiobiotin to biotin & FE705317 & $(534 / 664) 81 \%$ & $5.00 \mathrm{E}-179$ \\
\hline At4g11150 & EMB2448 & $\begin{array}{l}\text { Encodes a vacuolar } \mathrm{H}+-\mathrm{ATPase} \text { subunit } \mathrm{E} \text { isoform } 1 \text { which } \\
\text { is required for Golgi organization and vacuole function in } \\
\text { embryogenes }\end{array}$ & EX303864 & (474/662) $72 \%$ & 7.00E-99 \\
\hline At5g27540 & EMB2473 & $\begin{array}{l}\text { Encodes a protein with similarity to GTPases Involved in } \\
\text { embryogenesis, pollen tube growth and required for } \\
\text { mitochondrial development }\end{array}$ & FE711702 & (340/460) $73 \%$ & $3.00 \mathrm{E}-80$ \\
\hline At5g 18580 & FSI & $\begin{array}{l}\text { Encodes a protein similar in its C-terminal part to B' } \\
\text { regulatory subunits of type } 2 \mathrm{~A} \text { protein phosphatases }\end{array}$ & FE707962 & $(644 / 788) 81 \%$ & 0.0 \\
\hline At $2 g 30410$ & KIS & Encodes tubulin folding cofactor A & CV540440 & (198/259) $77 \%$ & $5.00 \mathrm{E}-53$ \\
\hline At1g67490 & KNF & $\begin{array}{l}\text { Encodes an alpha-glucosidase I enzyme that catalyzes the } \\
\text { first step in N-linked glycan processing }\end{array}$ & CV543073 & (339/478) $72 \%$ & $2.00 \mathrm{E}-65$ \\
\hline AY138461 & L1L & $\begin{array}{l}\text { Essential regulator of embryo development, defines a unique } \\
\text { class of plant HAP3 subunits }\end{array}$ & CV538670 & (239/296) $81 \%$ & $2.00 \mathrm{E}-78$ \\
\hline At5g 10480 & PAS2 & $\begin{array}{l}\text { Protein tyrosine phosphatase-like involved in cell division } \\
\text { and differentiation }\end{array}$ & CV530165 & (492/694) $72 \%$ & $6.00 \mathrm{E}-101$ \\
\hline At5g07500 & PEI & $\begin{array}{l}\text { Encodes an transcription factor required for heart-stage } \\
\text { embryo formation }\end{array}$ & EX303834 & (184/259) $71 \%$ & $1.00 \mathrm{E}-31$ \\
\hline At1g71440 & PFI & Encodes tubulin-folding cofactor E & FE701414 & (391/567) 69\% & $8.00 \mathrm{E}-57$ \\
\hline At $2 g 28000$ & SLP & $\begin{array}{l}\text { Encodes chaperonin- } 60 \text { alpha, a molecular chaperone } \\
\text { involved in Rubisco folding }\end{array}$ & FE711584 & $(596 / 744) 80 \%$ & $3.00 \mathrm{E}-78$ \\
\hline At2g18390 & TTN5 & Encodes a member of ARF-like GTPase family & CB542010 & (322/397) $81 \%$ & $2.00 \mathrm{E}-47$ \\
\hline At3g20630 & TTN6 & Encodes a ubiquitin-specific protease & CB542426 & (417/588) $70 \%$ & $4.00 \mathrm{E}-80$ \\
\hline At2g27170 & TTN7 & Protein required in cohesin complex & CV541843 & (338/436) $77 \%$ & $2.00 \mathrm{E}-98$ \\
\hline At5g16750 & TOZ & $\begin{array}{l}\text { Encodes a nucleolar localized WD- } 40 \text { repeat protein that is } \\
\text { preferentially expressed in dividing cells and is required for } \\
\text { regulated division planes and embryo development }\end{array}$ & CV533581 & (211/280) $75 \%$ & $3.00 \mathrm{E}-53$ \\
\hline At1g14610 & TWN2 & Required for proper proliferation of basal cells & CV540202 & (424/569) $74 \%$ & $1.00 \mathrm{E}-100$ \\
\hline At1g78580 & TPS1 & $\begin{array}{l}\text { Encodes an enzyme putatively involved in trehalose } \\
\text { biosynthesis }\end{array}$ & CB541509 & $(298 / 356) 83 \%$ & $1.00 \mathrm{E}-109$ \\
\hline At1g63700 & YDA & Member of MEKK subfamily & FE709393 & (188/250) $76 \%$ & $1.00 \mathrm{E}-44$ \\
\hline
\end{tabular}

(day/night) temperature, $75 \%$ relative humidity and $12 \mathrm{~h}$ photoperiod. The plants were watered once every 3 days.

To harvest seeds of defined age, individual flowers were tagged with threads on the day of flower opening. Mutant EMS and common bean seeds were isolated from the pods at 3, 6, 8, 9 and 12 days after pollination (DAP). For histological studies, the seeds were immediately immersed in fixation solution. For RNA extraction, the seeds were immediately frozen in liquid nitrogen and then stored at $-80^{\circ} \mathrm{C}$.
Histological studies

Seeds from both the wild-type and EMS-induced mutant were freshly harvested at 3, 6, 8, 9, and 12 DAP and fixed in $4 \%(\mathrm{w} / \mathrm{v})$ formaldehyde (freshly made from paraformaldehyde) and $1.2 \%$ glutaraldehyde in phosphate buffer $(7.4 \mathrm{~g}$ $\mathrm{NaH} 2 \mathrm{PO} 42 \mathrm{H} 2 \mathrm{O} ; 8.4 \mathrm{~g} \mathrm{Na} 2 \mathrm{HPO} 42 \mathrm{H} 2 \mathrm{O})$ for $24 \mathrm{~h}$ at $4{ }^{\circ} \mathrm{C}$, rinsed in phosphate buffer ( $\mathrm{PH} 6.6)$, dehydrated in a graded ethanol series $(30,50,70,90,95,100 \%(\mathrm{v} / \mathrm{v})$ and embedded in Technovit 7100 resin (Heraeus Kulzer $\mathrm{GmbH}$ ) for $48 \mathrm{~h}$. 
Sections were cut at $3 \mu \mathrm{m}$ on a Zeiss HM 360 microtome fitted with a tungsten-carbide knife, transferred to poly-L-lysine-treated slides (Sigma), and dried overnight at $40^{\circ} \mathrm{C}$. Staining was performed with Toluidine blue $\mathrm{O}$, as described by Gutmann (1995), and viewed with a Nikon Eclipse E800 fluorescence microscope (Japan). Pictures were taken with a JVC 3-CCD color video camera and images were handled with the Sony image Archive Plus program.

\section{Database searches}

The Arabidopsis sequenced genes published by Tzafrir et al. (2004) were retrieved using the lasted version of The Arabidopsis Information Resource (TAIR10) database (http://www.arabidopsis.org). These sequences were used as queries against the Genome Data-base (http://www.plant gdb.org). BLASTn searches were carried out to identify homologous Phaseolus vulgaris ESTs with a cutoff value of $\mathrm{e}^{-4}$.

\section{RNA extraction and RT-PCR}

Organ-specific expression of wild-type common bean was analyzed for leaves (2-week-old plants), stems (2-week-old plants), roots (2-week-old plants), and cotyledons (3-dayold seedlings), as well as flowers (0 DAP) and seeds (15 DAP) from 7-week-old plants. Samples were ground in liquid nitrogen, and total RNA was isolated by the Trizol reagent (Invitrogen), following the manufacturer's protocol.

For RT-PCR, $10 \mu \mathrm{g}$ of total RNA was treated with $10 \mathrm{U}$ of DNaseI (Fermentas) in DNAseI assay buffer for 30 min at $37^{\circ} \mathrm{C}$. Five microgram of total RNA was reverse transcribed using the Revert $\mathrm{Aid}^{\mathrm{TM}} \mathrm{H}$ Minus M-MuLV RT and Random hexamer primers (Fermentas) at $42^{\circ} \mathrm{C}$ for $1 \mathrm{~h}$ according to the manufacturer's instruction. Fragments were amplified from these cDNA pools using Taq DNA polymerase (Biolab's), following the manufacturer's procedure. An amplification of $18 \mathrm{~S}$ was used as an internal control.

Primer pairs were designed by Primer3 Input (version 0.4.0) software (Rozen and Skaletsky 2000) (http://www. frodo.wi.mit.edu/primer3/).

PCR amplification was performed for all genes using the following program: $3 \mathrm{~min}$ at $94^{\circ} \mathrm{C}, 30 \mathrm{~s}$ at $94^{\circ} \mathrm{C}, 45 \mathrm{~s}$ at $55-60^{\circ} \mathrm{C}$ (depending on the primers used, see Table 2) and $1 \mathrm{~min}$ at $72^{\circ} \mathrm{C}$. An elongation step at $72^{\circ} \mathrm{C}$ for $5 \mathrm{~min}$ was conducted for the last cycle. ABP1, FSI, L1L, TPS and Pv $18 \mathrm{~S}$ were amplified for a total of 25 cycles. ARP7, PFI, AML1, AUXR6, KIS, TTN6, TOZ and SLP were amplified under the same conditions for a total of 30 cycles. TTN5, TTN7, TWN2, YDA, BIO2, KNF, PAS2, PEI, EMB 2473 and EMB 2448 were amplified under the same RT-PCR conditions for a total of 34 cycles.
Reactions were performed in a Minicycler (BioRad iCycler) thermal cycler. The experiments were repeated three times. The amplified PCR products $(15 \mu \mathrm{l})$ were electrophoresed on a $1 \%(\mathrm{w} / \mathrm{v})$ agarose gel, stained with ethidium bromide, and scanned using an image analyzer.

\section{Real-time RT-PCR analysis}

Samples from the wild-type and EMS mutant of cultivar BAT93 were collected at 3, 6, 8, 9 and 12 DAP. Plant materials were grown in a glasshouse in pots.

Total RNA isolated from seed tissues was treated with DNAse I (Fermentas) to remove potential genomic DNA contamination. Five micrograms of DNA-free total RNA was then used to synthesize first-strand cDNAs using an oligo-p $(\mathrm{dT})_{15}$ primer and AMV reverse transcriptase (Roche), following the manufacturer's protocol.

Specific primers were designed using Primer3 (Rozen and Skaletsky 2000). PFI, (F5'-TCCCTGAGCATCTTTCCAGT-3'; R5'-TTGAATGAAGGGATGGTGGT-3'); PEI, (F5'-CAGACTCCGATGTTCCGTCT-3'; R5'-ACACTCG GTCCAGTCATGTG-3'); AML1, (F5'-TTCATCAGCCAA GCATTCAG- ${ }^{\prime}$; R5 $^{\prime}$-AATTGGATCTGCTGGAGTGG-3'); L1L, (F5'-AGGCAGGTAGCAGGAGACAA-3'; R5'-ATC TTGGCATGTGGAGGAAG-3'); TOZ, (F5'-AGATAAGG TTTGGGCCTTGG-3'; R5'-TTTGTCAGCTGCAGTGGA AT-3') and TTN6, (F5'-TAGCTGCCAGTCATCCTGAA-3'; R5'-TTTCCCAGCATTAGCTCGTT- $3^{\prime}$ ) were used in PCR to generate fragments of $200 \mathrm{bp}$. Real-time PCR reactions were performed using the ABI7500 FAST real-time PCR instrument (Applied Biosystems). As a control, the housekeeping gene $\mathrm{Pv} 18 \mathrm{~S}$ was amplified (F5'-TCGAAGCGA TCTTTTCGTAGA-3'; R5'-TTCTCAGTCGACTCGCTTT TT- $3^{\prime}$ ). PCR was conducted in $20 \mu$ of reaction volume containing $10 \mu \mathrm{l}$ syber-green mix (Fermentas), $0.1 \mu \mathrm{M}$ of each primer and $4 \mu \mathrm{l}$ of cDNA template under the following conditions: $94^{\circ} \mathrm{C}$ for $3 \mathrm{~min}$, and 40 cycles of $94^{\circ} \mathrm{C}$ for $30 \mathrm{~s}$, $59^{\circ} \mathrm{C}$ for $45 \mathrm{~s}$, and $70^{\circ} \mathrm{C}$ for $1 \mathrm{~min}$. Real-time PCR reactions were carried out in triplicate and the results were analyzed following the manufacturer's advice (Applied Biosystems). Methods determining the relative gene expression levels were as described by Livak and Schmittgen (2001).

\section{Results}

Histological studies of the embryo development of Phaseolus vulgaris EMS mutagenized plants deficient in seed development

In order to characterize Phaseolus plants deficient in seed development, we isolated seven plants showing homozygous failure in seed development from the second 
Table 2 Primers used for RT-PCR analysis

\begin{tabular}{|c|c|c|c|}
\hline GenBank (db EST) accession number & Forward primer $5^{\prime}-3^{\prime}$ & Reverse primer $5^{\prime}-3^{\prime}$ & $\operatorname{Tm}\left({ }^{\circ} \mathrm{C}\right)$ \\
\hline CV529696 & F-GCACTCGTTCTGGCTTCTTC & R-TGACCAGTCCTCGTATGCAA & 57 \\
\hline EY457929 & F-CCAGAGAAGAGCATTGCACA & R-CCACTGTGTGCCACCAATAC & 59 \\
\hline FE711613 & F-GACCGATAACCCAACATTCG & R-TGTGGTTAACAGCACCCTCA & 55 \\
\hline FE695779 & F-GAGTACCAAAAAGGCGGAGA & R-TGACAAGGAGTGGAGCAGTC & 55 \\
\hline FE705317 & F-GCTGCATGGAGGGATACACT & R-GAGCTTTTGGGAGAAGTCCA & 55 \\
\hline EX303864 & F-GGTGAGGTGGTGTGGGTTAG & R-ACCCCACCAGACCAGTACAT & 59 \\
\hline FE711702 & F-TATTGAAAAGGGGCGTCTTG & R-CCAATCCAAGGACTTTCAGG & 56 \\
\hline FE707962 & F-GAGTCCAGAGATTGGCGAAG & R-GATGCAAGCTTTTCCTCGTC & 55 \\
\hline CV540440 & F-CAACACAGTGTGCAACACCA & R-GAGAAGAGGGCTCATGCAAC & 57 \\
\hline CV543073 & F-GAAAGAAGTGGAGGCAGGAA & R-CTTACTGCCTTGGTGGCACT & 60 \\
\hline CV538670 & F-CTGTCACCATGGAAAGTGGA & R-GCGAGCATTCGGTTCAGTAT & 55 \\
\hline CV530165 & F-TAACCCTCTTCGTTGGATGG & R-GTTGGGCATCCTTATGCAGT & 57 \\
\hline EX303834 & F-TCCTCACCGGAGATGTTTTC & R-GGCAGAACCCTTAGTTGCTC & 55 \\
\hline FE701414 & F-CTGCCCTGAGGACAATCAAT & R-CAGGACTAGTATGCAACCTGGA & 60 \\
\hline FE898061 & F-GAGGATTCCTGGTCTTTGGA & R-TAGCAAGGCGGTCTTCTTGT & 55 \\
\hline CV533581 & F-AGATAAGGTTTGGGCCTTGG & R-ATGATCTTCAGCCGCTCTCT & 55 \\
\hline CV540202 & F-TGCACTGGTCTCATACACAGC & R-CACAGTAACCGCCTGTGTTC & 57 \\
\hline FE705839 & F-TCAAGCGGAAAGAGAAGGAA & R-GCTTCCAAGTTCAGCACCTT & 60 \\
\hline CB542426 & F-AGCTGCCAGTCATCCTGAAT & R-GTACCCATCCTGCCTCCATA & 57 \\
\hline CV541843 & F-CTTCGAAGAGTGCCCAGTGT & R-ATCCGGAGGGGAGAGTAGAA & 59 \\
\hline CB541509 & F-GAGGATTCCTGGTCTTTGGA & R-TAGCAAGGCGGTCTTCTTGT & 55 \\
\hline FE709393 & F-GGACTACACAAGGGGCAAAA & R-CCCTATTTGCATTCCTCGAA & 55 \\
\hline
\end{tabular}

generation of an EMS-mutagenized M1 plant (522) of Phaseolus vulgaris L. (Silué et al. 2006). We then characterized these selected plants by comparing their embryo development pattern to the Phaseolus wild-type embryo during seed development.

In the wild-type plants, the pattern of seed development is similar to many flowering plants. In contrast, the EMS mutant showed disruption in normal seed development, leading to embryo abortion. Mutant embryo-defective seeds are readily distinguishable as shriveled and brown seeds from the wild-type green seeds in immature pods (Fig. 1).

The average fresh weight of the seeds is shown in Figure 2. During the first week after fertilization, both abortive (EMS mutant) and control (wild-type) seeds showed similar weights. At 12 DAP, the fresh weight of control seeds increased twofold (Fig. 2). At 30 DAP, the maximum fresh weight was attained for the wild-type, with an average weight of $488 \mathrm{mg} \mathrm{seed}^{-1}$. For abortive seeds the maximum fresh weight $\left(32 \mathrm{mg} \mathrm{seed}^{-1}\right)$ was obtained at 15 DAP (Fig. 2).

To determine at what stage of embryogenesis the EMS mutant phenotype was first observed, a developmental series of EMS mutant embryo sections was obtained and compared with those of wild-type embryos. The embryogenesis of a normal and mutant embryo viewed with
Nomarski optics is shown in chronological order in Fig. 3. Development of the EMS mutant embryos was considerably delayed compared with wild-type embryos.

In the wild-type, the embryo began to develop shortly after fertilization. At about 3 DAP, the embryo reached the early globular stage of development (Fig. 3a). The cells of the embryo proper had dense cytoplasm. The suspensor attached directly to the inner surface of the inner integument. The cells of the suspensor were more vacuolated than the cells of the embryo proper. At about 8 DAP, the embryo reached the heart-shaped stage with the formation of cotyledons (Fig. 3e). The cotyledons expanded rapidly by vacuolation and gradually extended towards the chalazal end of the seed (Fig. 3g). About 12 DAP, the cotyledons continued to expand with a well-defined embryo axis (Fig. 3i). Both the root and the shoot apical meristems were well defined. At this stage, the embryo grew rapidly; it occupied most of the endosperm cavity and storage products began to accumulate within embryo cells.

In abortive genotypes (EMS mutant), the first stage of seed development was similar to the control genotype. At 3 DAP, embryos were at the early globular stage (Fig. 3b), and their tissue organization appeared to be normal. After this stage, embryo development was delayed or arrested. At 8 DAP, EMS mutant embryos did not exhibit the characteristic 
(a)

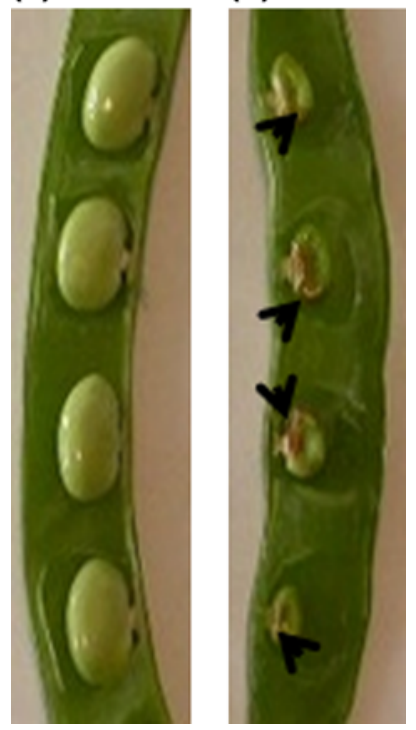

Fig. 1 Phenotypical analysis of wild-type and EMS mutant seeds of Phaseolus vulgaris (15 DAP). a Immature pod obtained by selfpollination of a wild-type plant. b Immature pod obtained by selfpollination of EMS mutant

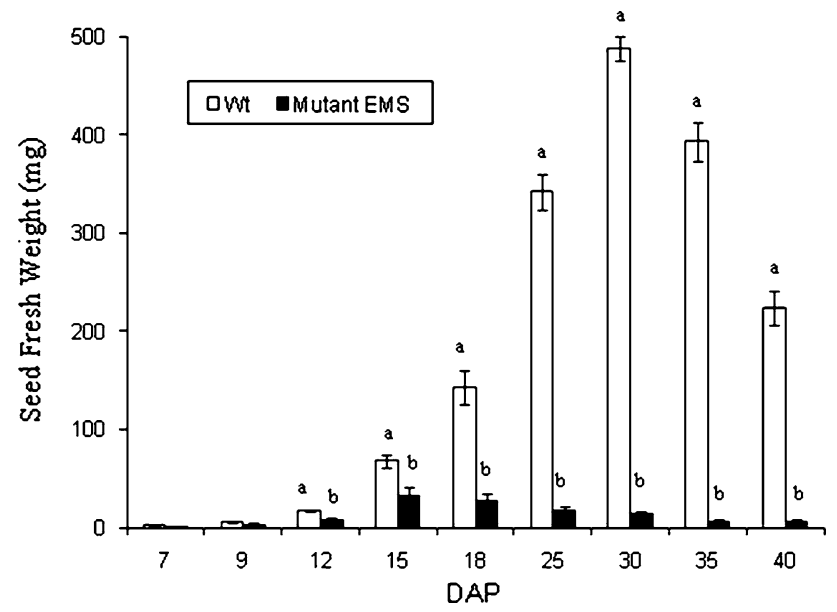

Fig. 2 Fresh weight accumulation of wild-type and EMS mutant seeds. Data shown represent mean values obtained from three different plants and the errors bars indicate standard deviation. Significant difference $(P<0.05)$ detected by Tukey's multiple comparison test is shown by different letters above the bars

heart shape and appeared elongated (Fig. 3f) by the time the wild-type embryo had become heart-shaped (Fig. 3e).

Mutant embryos appeared wider than wild-type embryos and were defective at the heart and later stages, with abnormalities in cell morphology. Unlike the torpedo shape observed for wild-type embryos (Fig. 3g), EMS mutant embryos displayed a heart-like shape (Fig. 3h). The characteristic wild-type bent-cotyledon or mature embryo stages were not observed in mutant EMS.
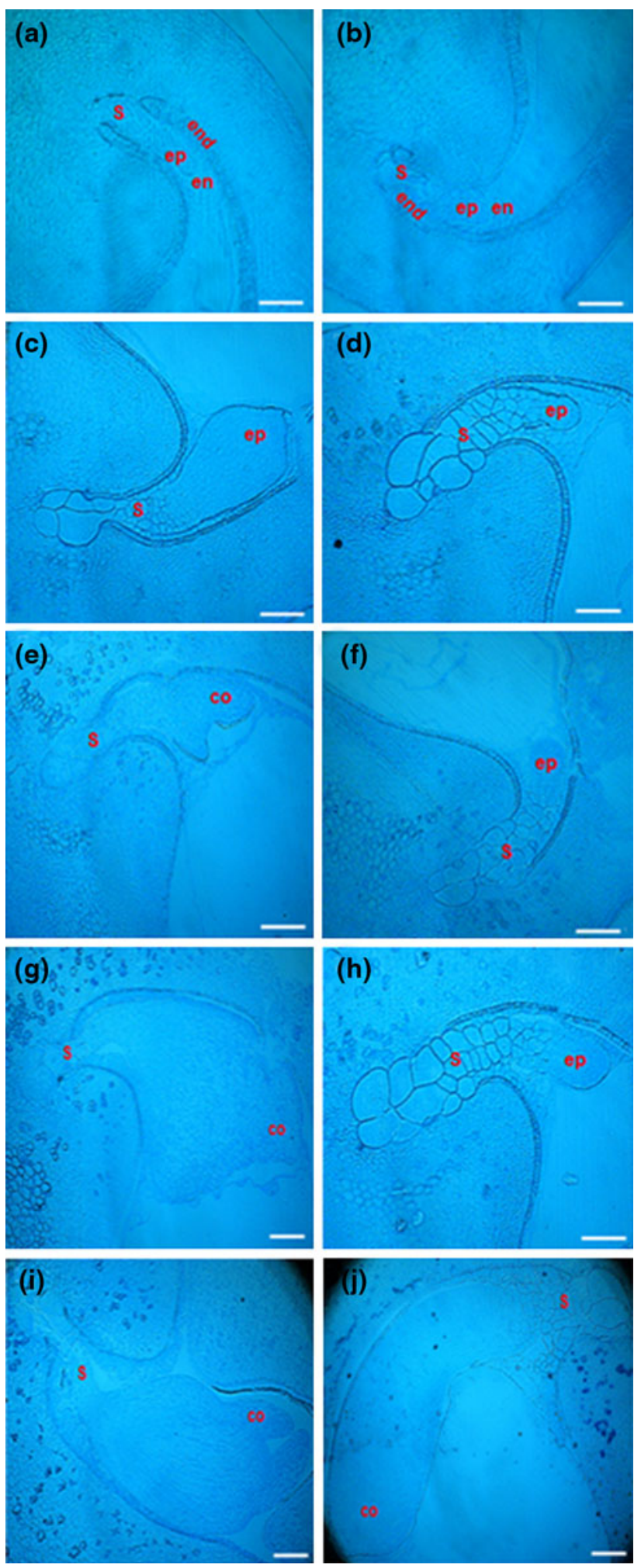

Fig. 3 Embryo development of EMS mutant in comparison to wildtype common bean (wild-type $\mathbf{a}, \mathbf{c}, \mathbf{e}, \mathbf{g}, \mathbf{i} ;$ EMS mutant $\mathbf{b}, \mathbf{d}, \mathbf{f}, \mathbf{h}, \mathbf{j}$ ). Embryos reached the early globular stage at 3 DAP $(\mathbf{a}, \mathbf{b})$, the globular stage at $6 \mathrm{DAP}(\mathbf{c}, \mathbf{d})$, the heart stage at $8 \mathrm{DAP}(\mathbf{e}, \mathbf{f})$, the torpedo stage at 9 DAP $(\mathbf{g}, \mathbf{h})$, and the bent cotyledon stage at 12 DAP (i, j). Co cotyledon; en endosperm; end endothelium; ep embryo proper; $s$ suspensor. Scale bars $100 \mu \mathrm{m}$ 
In all embryo stage development, the suspensor appeared to develop but showed dramatic evolution. At the early globular stage, the embryo contained a morphologically normal suspensor and embryo (Fig. 3b). Abnormal divisions in the suspensor first appeared at the globular stage (Fig. 3d) and continued during subsequent growth (Fig. 3f, h, j). Cell divisions continued in both embryo and suspensor through to the torpedo stage, resulting in an elongated embryo and a suspensor often being the size of the embryo (Fig. 3f, h). At 12 DAP (Fig. 3j), the embryo formed elongated small cotyledons, but did not occupy the whole seed as in the wild-type samples.

\section{Expression of selected ESTs in different organs}

An in silico analysis was performed in order to identify genes involved in Phaseolus embryo development and specifically expressed in immature seeds. A total of 250 genes required for normal embryo development in Arabidopsis thaliana were used as an initial dataset (Tzafrir et al. 2004). Using the BLASTn program, the coding regions of the different genes from Arabidopsis were used as queries to search the EST sequences available from Phaseolus for homology. A total of 22 ESTs expressed in Phaseolus showed significant homology with their homo$\log$ in Arabidopsis thaliana (Table 1). Specific primers were designed for each of the 22 selected ESTs (Table 2) and the transcript expression in various tissues was analyzed by RT-PCR (Fig. 4). All 22 selected ESTs were found to be expressed in Phaseolus vulgaris with different but overlapping expression patterns, confirming that all genes are active in common bean tissues.

The expression level of EST Phaseolus vulgaris ABP1, FSI, L1L and TPS is relatively high in this species. The exponential stage for these genes and internal control Pv18S was detected from about 25 cycles (Fig. 4). The signals of other selected ESTs are lower in this species and were detected from 30 to 34 cycles. Most Phaseolus vulgaris ESTs had a higher expression in seeds at 15 DAP compared with other tested tissues. The expression profiles revealed that the seed, flower, cotyledon and leaf tissues exhibited a higher expression of common bean EST than stem and root tissues. AML1, L1L and PAS2 were highly expressed only in seeds at 15 DAP. Transcripts from PFI and TWN2 were more readily detected in seeds and leaves than in other tissues. SLP, TOZ and ARP7 transcripts were detected in all tissues except stems. Interestingly, the expression of ABP1, SLP, KIS and TPS was highly detected in seed and cotyledon tissues, suggesting a possible role of these genes in embryo organogenesis. YDA, PEI, L1L and PAS2 transcripts were not detected in leaf tissues. AUXR6, BIO2, EMB2448, KNF and TWN2 transcripts were detected in seed, leaf and floral tissues, but not

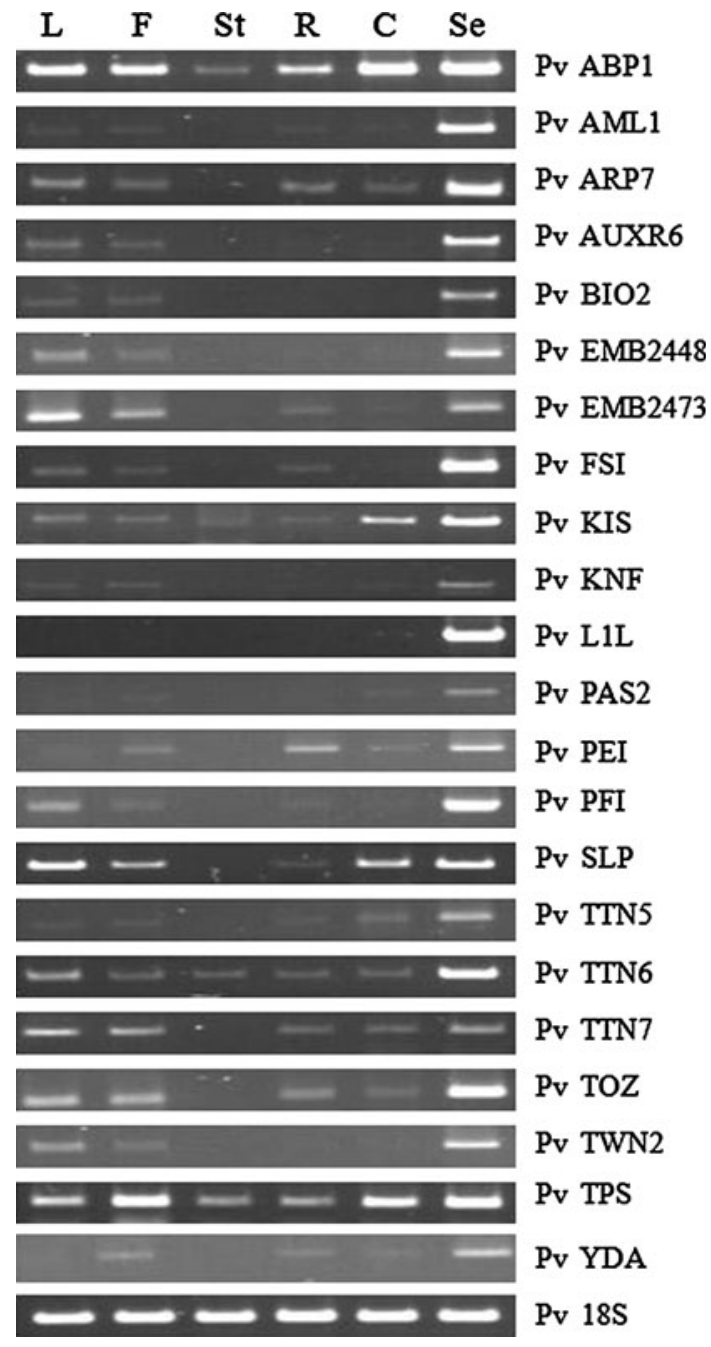

Fig. 4 Expression patterns of selected genes in various tissues by RTPCR. RT-PCR products using gene-specific oligonucleotide primers to assess expression levels of $\mathrm{Pv}$ ESTs and $\mathrm{Pv} 18 \mathrm{~S}$ in tissues from Phaseolus vulgaris were analyzed on $1 \%$ agarose gel. Various numbers of PCR cycles were tested, as described in "Materials and methods". $L$ leaves; $F$ flowers; $S t$ stems; $R$ roots; $C$ cotyledons; $S e$ seeds

in stems and roots or cotyledons. ARP7, TOZ and TTN5 transcripts were detected in all tested tissues except stems. Transcripts were not detected in stem or cotyledon tissues for EMB2473 or the FSI gene.

TPS, KIS, TTN6 and ABP1 transcripts were detected in all tissues, although at different levels. Transcripts corresponding to all selected genes were abundant in seeds, but were low, scarce or undetectable in other tissues (Fig. 4).

Real-time RT-PCR pattern analysis of the differential expression genes during seed development

Six ESTs which are related to transcription factors and/or signal transduction and highly expressed in common bean 
seed tissues compared with other tissues (L1L, PEI, TOZ, AML1, PFI, and TTN6) were selected for further quantitative real-time RT-PCR analysis in order to evaluate the expression profile of these genes during common bean embryogenesis. In order to investigate if these six genes could be involved in Phaseolus embryogenesis, their expressions in wild-type Phaseolus vulgaris and the EMS mutant were compared from 3 to 12 DAP (Fig. 5).

Low relative transcript levels were shown for TTN6, PEI and PFI genes in various stages of seed development compared with AML1, TOZ and L1L. The transcript level of all genes studied changed more than twice during the time course. In general, the corresponding transcripts for selected genes showed diverse temporal expression patterns throughout seed development. In EMS mutant, the expression of TOZ, TTN6, AML1, PFI and L1L followed a bell-shaped pattern that increased through the early developmental stages, peaked at 8 DAP, and then decreased. In the wild-type, TTN6, L1L and PFI genes were characterized by a distinctly different profile with maximum expression later in development (12 DAP). In contrast, AML1 showed high expression at 3 DAP and low expression for other stages. All genes showed lower expression at 6 DAP. Our analysis also revealed that in EMS mutant TOZ, L1L, TTN6, PFI and AML1 genes showed maximum expression at 8 DAP, whereas for PEI it was 12 DAP.

The expression pattern of all tested genes was affected in EMS mutant compared with the wild-type during seed development, particularly at later stages ( 9 and 12 DAP) for TOZ, L1L, TTN6 and PFI. Alteration in expression occurred at an early stage (3 DAP) for all selected genes, but particularly for the AML1 gene, with a 350-fold reduction in expression.

\section{Discussion}

The Arabidopsis embryo-defective mutant approach is particularly useful for identifying important genes involved in embryo development and for understanding the function of expressed genes and defining their role in developmental processes (Tzafrir et al. 2003). Some embryo-defective mutants are blocked at a particular stage of the process necessary for embryo viability and development; other mutants have defects in important developmental regulators or in simple metabolism functions.

Embryo-defective mutations can be induced by physical, biological and chemical means such as EMS mutagenesis, which is a standard technique used to induce point mutation in DNA. EMS mutations can be difficult to interpret, but they can also be informative because they can reveal common genetic components of seemingly unrelated developmental processes and can indicate multiple roles for a gene in development (Vernon et al. 2001).

In order to study the mechanism of Phaseolus embryogenesis by identifying and characterizing the genes involved in embryogenesis, we obtained mutant plants producing degenerate seeds at different stages in seed development (Silué et al. 2006) using EMS mutagenesis.

We first characterized these selected mutant plants by comparing their embryo pattern with Phaseolus wild-type embryos during seed development. In an abortive genotype, embryo development progresses normally until the globular stage. After this stage, embryo development is delayed or arrested. The marked difference in embryo development between the control and the abortive genotype is probably caused by the differences observed in suspensor development. Abnormality of suspensor development is one of the main causes of embryo abortion in flowering plants (Schwartz et al. 1994). The suspensor is the first differentiated structure produced by the developing embryo (Yeung and Sussex 1979). More recent evidence suggests that the suspensor plays an active role in supporting early development of the embryo proper by providing nutrients and growth regulators (Laux and Jürgens 1997; Rademacher and Weijers 2007). Interestingly, Liu et al. (1993) suggested that the suspensor and embryo proper constituted an attractive system for identifying molecular mechanisms that mediate developmental interactions during early embryogenesis.

Our data indicate that the EMS mutant embryos develop normally but more slowly than wild-type embryos during the early stages of seed development and fail to activate a wide range of embryo-specific programs after the heart stage. In general, EMS mutant embryos showed a suspensor hypertrophy, resulting in a smaller and delayed embryo proper, compared with the wild-type embryos (Fig. 3). During the last stages of seed development in the wild-type samples, the suspensor size started to decline after 9 DAP, until it disappeared completely. In contrast, in EMS mutant, the suspensor continued to growth after 9 DAP (Fig. 3). These observations support the hypothesis that the continued growth of the suspensor in the wild-type samples is inhibited by the embryo proper during the final stages during normal development (Yeung and Meinke 1993). In EMS mutant, the embryo proper lost the capacity to inhibit the suspensor growth. The latter continued to grow and contained longer cells in the basal part than in the wild-type samples. In the wild-type common bean, the embryo proper became longer than the suspensor at $6 \mathrm{DAP}$ (Fig. 3c), whereas in the EMS mutant this characteristic was not evident. Our observations suggest that EMS mutant disruption of development in the embryo proper can lead to suspensor disruption and partial transformation of the embryo. 
TOZ
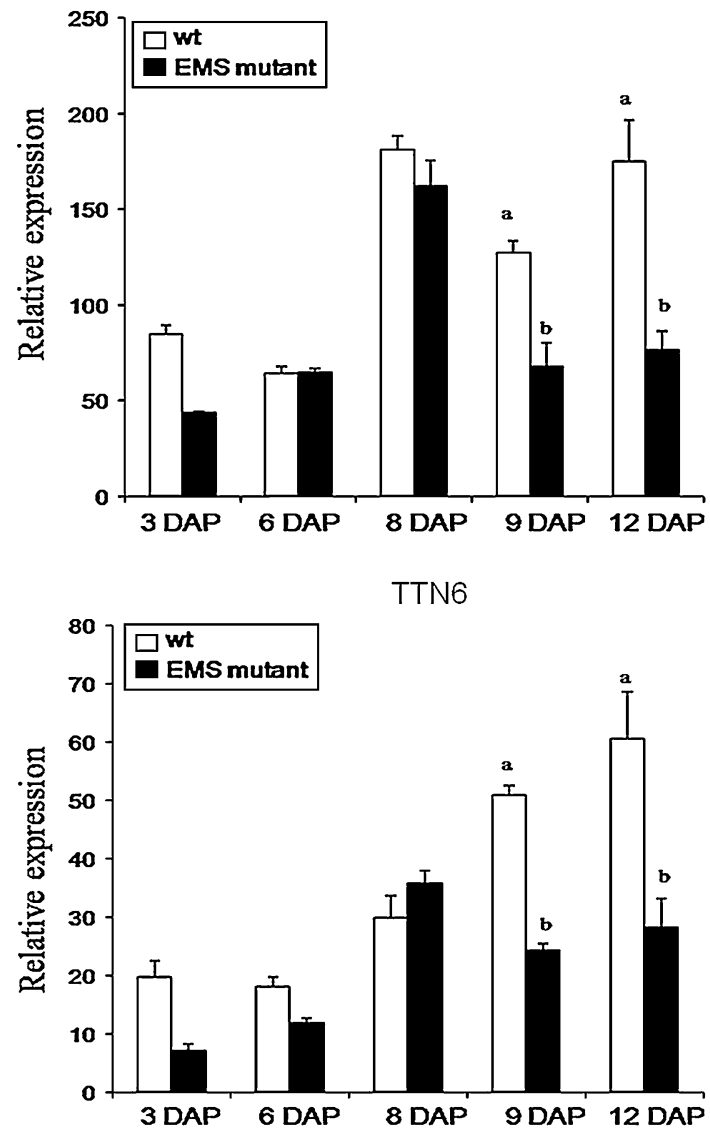

AML1

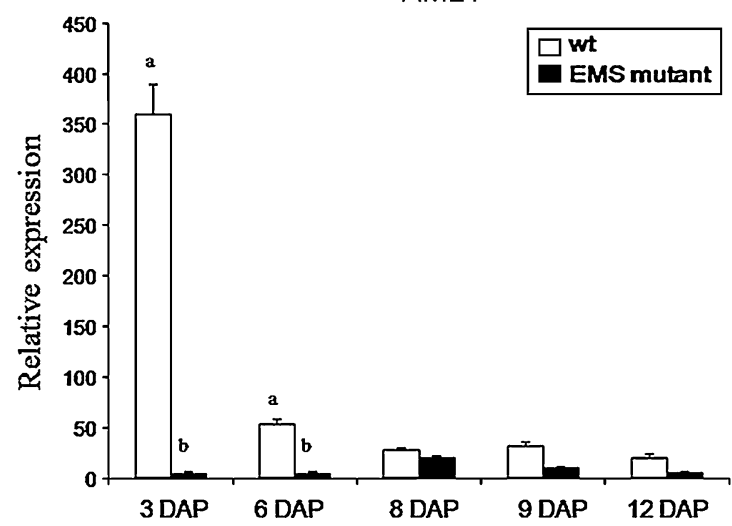

Fig. 5 Real time RT-PCR measurements of TOZ, L1L, PFI, AML1, TTN6 and PEI expression in developing wild-type and EMS mutant seeds. The relative mRNA levels of individual genes were normalized with reference to the housekeeping gene 18S. Data shown represent

The altered pattern of suspensor development in the EMS mutant might have further shifted the equilibrium of nutriment competition in favor of the maternal tissues. Suspensor abnormalities could be a direct result of reduced ability to transfer nutrients from the maternal tissue. The synthesis and accumulation of nutrients and storage protein bodies in the maternal tissue layers could result in the
L1L

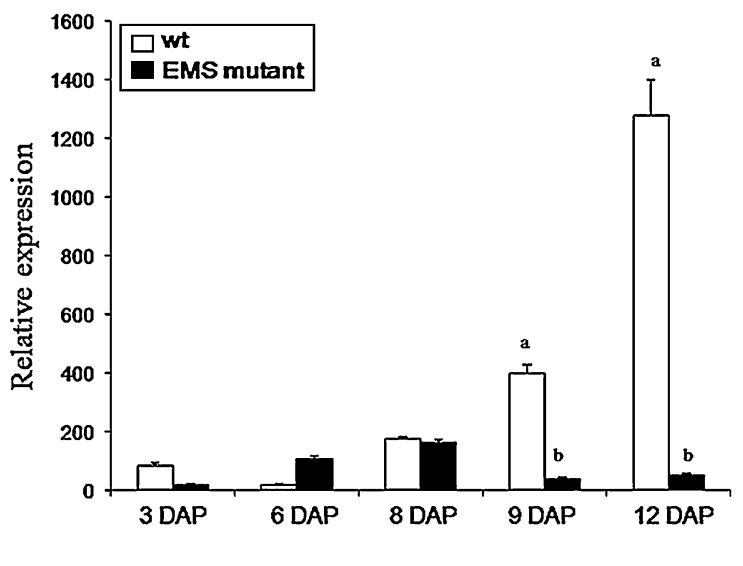

PFI
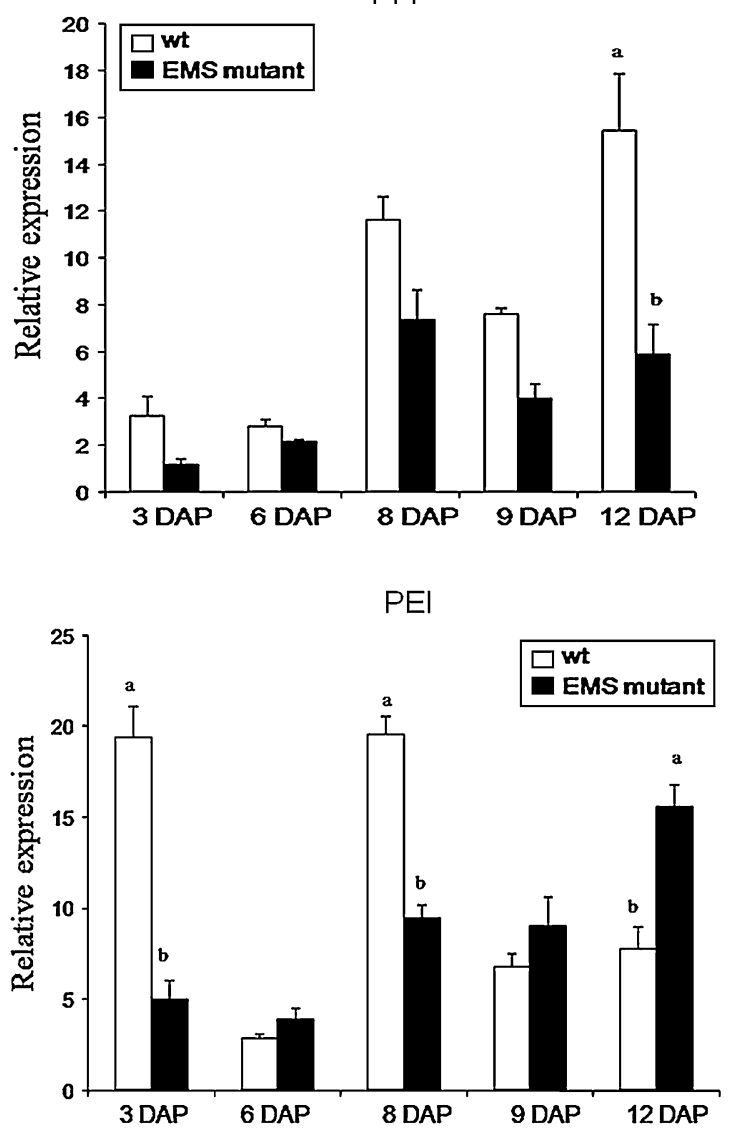

mean values obtained from three independent amplification reactions and the errors bars indicate standard deviation. Significant difference $(P \leq 0.05)$ detected by Tukey's multiple comparison test is shown by different letters above the bars

failure to translocate nutrients to the developing embryo, leading to embryo abortion.

Identical results were obtained in abnormal suspensor (sus) mutants (Schwartz et al. 1994), and raspberry (rsy) mutants (Apuya et al. 2002) of Arabidopsis thaliana.

The objective of the second stage of this work was to identify genes whose expression is specific in Phaseolus 
immature seeds. Despite the importance of common bean as a food crop legume, very little EST information is publicly available (Graham et al. 2004). Only 575 ESTs from common bean and 20120 ESTs from the related species, runner bean (Phaseolus coccineus), have been deposited in the GenBank EST database (Ramirez et al. 2005).

We used in silico analysis to search these publicly available Phaseolus ESTs with Arabidopsis sequences known to be involved in seed development. Twenty-two ESTs showing significant homology with the Arabidopsis thaliana genes were selected (Table 1). The morphological defects associated with mutations in each of the 22 corresponding genes had been described and their expression during zygotic embryo development had been analyzed in Arabidopsis and other species, but not reported for common bean.

Arabidopsis LEAFY COTYLEDON1-LIKE (L1L) gene is a central regulator of embryogenesis that plays key roles in processes occurring in both the early and late phases. $\mathrm{L} 1 \mathrm{~L}$ is a member of the CCAAT binding factor (CBF) class of eukaryotic transcriptional activators (Alemanno et al. 2008). It is also required for normal embryo development (Kwong et al. 2003). $l 1 l$ RNAi mutants provoked the arrest of embryo development at different stages with a range of morphological phenotypes (Kwong et al. 2003). Some embryos arrested at the globular stage. Other mutants arrested at later embryonic stages and had reduced cotyledons. The expression of L1L was strongly detected in the protoderm, confirming the role of L1L genes in coordinating primary events leading to embryonic competence (Harada 2001; Kwong et al. 2003) and their involvement in establishing a cellular environment that promotes embryo development (Lotan et al. 1998). AXR6 is involved in auxin response during early seed development. Mutants axr6 show dramatically aberrant patterns of cell division, leading to defects in the cells of the suspensor, root and hypocotyl precursors and vascular pattern in cotyledons (Hobbie et al. 2000). The ABP1 gene encodes an auxin receptor mediating auxin-regulated cell expansion and is required for organized cell elongation and division in Arabidopsis embryogenesis. Mutants abpl showed slow proliferation and reduced cell division, and abnormal seeds arrested at the globular stage (Chen et al. 2001). The PEI gene encodes an embryo-specific transcription factor required for the globular-to-heart stage transition. Mutant peil interrupts embryogenesis at the heart stage $(\mathrm{Li}$ and Thomas 1998). Sugars such as trehalose play a pivotal role in embryogenesis, controlling many aspects of seed growth and development. The biosynthesis of trehalose involves the formation of trehalose-6-phosphate from glucose-6phosphate and UDP-glucose by the enzyme trehalose-6phosphate synthase (TPS). Mutant tps showed perturbation in trehalose signalling that led to the disruption of cell division and deregulation of cell wall biosynthesis, with the arrest of embryo development at the torpedo stage (Eastmond et al. 2002; Gomez et al. 2006). The valyl-tRNA synthase gene (TWN2) mutation induces a defect at an early stage of embryogenesis and arrests apical cell development, followed by abnormal proliferation of the basal cell to produce secondary embryos (Zhang and Somerville 1997). Mutant bio2 shows embryo arrest at the globular stage related to deficiency in biotin synthesis as a support to rapid cell division (Patton et al. 1998). The KIS gene encodes an ortholog of mammalian proteins involved in tubulin folding co-factors that play an essential role in the polymerization of microtubules from $\alpha / \beta$ tubulin heterodimers. Microtubules are intracellular structures required for a variety of processes, particularly the establishment of the special organization of cells, and cell morphogenesis. Mutant embryo kis consists of only one or a few grossly enlarged cells with one or more large nuclei and abnormal endosperm that fails to cellularize and contains only a few enlarged nuclei, although embryonic development stopped (Steinborn et al. 2002). The generation of homozygous mutant Arabidopsis Minute-like 1 amll showed disruption in most cell division processes and development stopped completely at an early embryonic stage (Weijers et al. 2001). Alteration in mitosis was reported for titan (ttn) mutants, which represent another interesting class of mutants with defects in embryo and endosperm development (Liu and Meinke 1998). Nine TITAN genes have been identified in Arabidopsis, including TTN5. Embryo development in TTN5 mutant seeds is limited to the formation of a few giant cells. The number of endosperm nuclei is reduced and endosperm cellularization is blocked (McElver et al. 2000). Another TITAN gene product (TTN6) is related to the isopeptidase $\mathrm{T}$ class of deubiquitinating enzymes that recycle polyubiquitin chains following protein degradation. Mutant $t$ tn 6 is reported to stop embryo development at the globular stage (Tzafrir et al. 2002). The TORMOZ (TOZ) gene encodes a nucleolar protein containing WD repeat domains. Disruption of the TOZ gene results in cell division defects and an arrested embryo at the globular stage (Griffith et al. 2007). ARP7 are actin-related proteins that are localized in the nucleus and involved in chromatin dynamics and transcriptional regulation. Homozygous mutants showed embryos that arrested at or before the torpedo stage of development (Kandasamy et al. 2005).

We used RT-PCR to validate our selection procedure. The expression of the 22 selected genes was confirmed in different organs (Fig. 4). Transcripts corresponding to L1L, AML1, BIO2 and PAS2 were abundant only in seeds and were slightly detectable or undetectable in leaves, flowers, roots, stems and cotyledons. The transcripts of the others 
genes were not particularly detected in seed tissues but also in leaves, flowers, stems, roots and cotyledons, although the expression levels were generally lower in these five organs than the seed tissues. The RT-PCR experiments and the presence of genes known to be specifically expressed in seed demonstrate that the in silico selection procedure identifies genes specifically, or at least predominantly, expressed in developing Phaseolus seeds.

In order to have a better insight into the involvement of the identified genes in the complex process of Phaseolus embryogenesis, we monitored the expression of represented genes such as TTN6, TOZ, PFI, AML1, PEI and L1L which are related to transcription factors and/or signal transduction, during the Phaseolus embryogenesis process using quantitative real-time PCR in the wild-type and EMS mutant. All these genes have been reported to be expressed in Arabidopsis zygotic embryogenesis and are important for cell survival, as described above. Mutation in these genes affects embryo development and leads to their abortion. Our results showed that the expression of all six selected genes was significantly affected in the the EMS mutant compared with the wild-type. Highly significant and specific down regulation was revealed for the AML1 gene in EMS mutant seeds at 3 DAP, whereas L1L, TOZ and TTN6 genes showed significant down regulation at 9 and 12 DAP.

We do not know, however, if one of these genes is directly affected by the EMS mutation. These results indicate that these genes are differentially expressed during common bean seed development; their regulation is likely to occur down-stream of genes more directly involved in initiating embryo development. The delay in the increase of their expression could be due to alteration in many biological processes. Interestingly, our data showed that cell division was markedly reduced in EMS mutant and this may be enough to account for the smaller size of the mutant embryos and seed fresh weight (Fig. 2). This reduction in cell division could be directly attributable to perturbation of the cytokinesis mechanism (Sollner et al. 2002). In addition, the control of embryo growth during seed development is tightly regulated at the level of cell division (Raz et al. 2001). Alternatively, TOZ and TTN6 genes were found to be required for normal mitotic division during Arabidopsis embryogenesis (Tzafrir et al. 2002; Griffith et al. 2007). The altered cell division in EMS mutant as well as the level of TOZ and TTN6 gene transcripts at different stage of seed development suggested that TOZ and TTN6 genes could also play a direct role in Phaseolus in regulating cell division. Interestingly, the transcript levels of several genes required for controlling embryo and seed development, such as PEI (Li and Thomas 1998), and for coordinating the morphogenesis phases, such as L1L (Chiappetta et al. 2009), were altered in EMS mutant relative to the wild-type (Fig. 5). The observed alteration in cell division and cell differentiation, and the defect altering embryo development in EMS mutant, could result from the down regulation of several genes required in embryo development, such as TOZ, TTN6, L1L, AML1, PFI and PEI. Altogether, all genes were down regulated in EMS mutant versus wild-type seeds, possibly reflecting the lower biosynthetic and metabolism activity of EMS mutant seeds. In addition, TTN6, L1L, TOZ, PFI, AML1 and PEI represent various functional categories during seed development, as shown in higher plants such as Arabidopsis. We therefore suggest that the effect of EMS mutagenesis on Phaseolus embryogenesis induces a general alteration of the mechanism of seed development.

Our study demonstrates the reliability of in silico analysis methods for identifying genes involved in Phaseolus seed development.

\section{Conclusion}

Few studies have been carried out in order to gain better insight into the mechanism of Phaseolus embryogenesis; the details of molecular events occurring during its developmental process are unclear. The present study was therefore undertaken to understand of the structural pattern of Phaseolus embryo development.

Embryos from EMS mutant showed abnormalities mainly in suspensors and cotyledons at the globular, heart and cotyledon stages. During embryo development in mutagenized samples, the suspensor with large cells disturbed the development of the embryo, which aborted before seed maturity, which was not the case in the wildtype samples.

The in silico analysis approach used in this study provides new information about Phaseolus embryo development. We described the identification and tissue-specific expression of 22 new highly expressed mRNAs during the early stages of seed development in common bean.

Pattern analysis for six selected genes, demonstrated that their expression profiles were quantitatively inconsistent for wild-type and EMS mutant. RT-PCR analysis suggested that some selected ESTs might provide new targets for the molecular characterization of Phaseolus seed development.

\section{References}

Alemanno L, Devic M, Niemenak N, Sanier C, Guilleminot J, Rio M, Verdeil JL, Montoro P (2008) Characterization of leafy cotyledon1-like during embryogenesis in Theobroma cacao L. Planta 227:853-866 
Apuya NR, Yadegari R, Fischer RL, Harada JJ, Goldberg RB (2002) RASPBERRY3 gene encodes a novel protein important for embryo development. Plant Physiol 129:691-705

Baster P, Ledwon A, Gli wicka M, Trojanowska A, Gaj MD (2009) Arabidopsis tanmei/emb 2757 embryo mutant is defective for in vitro plant morphogenesis. Plant Cell Tiss Organ Cult 99:305-312

Ben C, Hewezi T, Jardinaud MF, Bena F, Ladouce N, Moretti S, Tamborindeguy C, Liboz T, Petiprez M, Gentzbittel L (2005) Comparative analysis of early embryonic sunflower cDNA libraries. Plant Mol Biol 57:255-270

Bishop-Hurley SL, Gardner RC, Walter C (2003) Isolation and molecular characterization of genes expressed during somatic embryo development in Pinus radiata. Plant Cell Tiss Organ Cult 74:267-281

Chandler JW (2008) Cotyledon organogenesis. J Exp Bot 59: 2917-2931

Chen JG, Ullah H, Young JC, Sussman MR, Jones AM (2001) ABP1 is required for organized cell elongation and division in Arabidopsis embryogenesis. Genes Dev 15:902-911

Chiappetta A, Fambrini M, Petrarulo M, Rapparini F, Michelotti V, Bruno L, Greco M, Baraldi R, Salvini M, Pugliesi C, Bitonti MB (2009) Ectopic expression of LEAFY COTYLEDON1-LIKE gene and localized auxin accumulation mark embryonic competence in epiphyllous plants of Helianthus annus $\times \mathrm{H}$. tuberosus. Ann Bot 103:735-747

Dong J, Keller WA, Yan W, Georges F (2004) Gene expression at early stages of Brassica napus seed development as revealed by transcript profiling of seed abundant cDNAs. Planta 218: 483-491

Eastmond PJ, Van Dijken AJH, Spielman M, Kerr A, Tissier AF, Dickinson HG, Jones JDG, Smeekens SC, Graham IA (2002) Trehalose-6-phosphate synthase 1, which catalyses the first step in trehalose synthesis, is essential for Arabidopsis embryo maturation. Plant J 29:225-235

Errampalli D, Patton D, Castle L, Mickelson L, Hansen K, Schnall J, Feldmann K, Meinke D (1991) Embryonic lethal and T-DNA insertional mutagenesis in Arabidopsis. Plant Cell 3:149-157

Gomez LD, Baud S, Gilday A, Li Y, Graham A (2006) Delayed embryo development in the ARABIDOPSIS TRHALOSE-6PHOSPHATE SYNTHASE 1 mutant is associated with altered cell wall structure, decreased cell division and starch accumulation. Plant J 46:69-84

Graham MA, Silverstein KAT, Cannon SB, Van den Bosh KA (2004) Computational identification and characterization of novel genes from legumes. Plant Physiol 135:1179-1197

Griffith ME, Mayer U, Capron A, Ngo QA, Surendrarao A, McClinton R, Jürgens G, Sundaresan V (2007) The TORMOZ gene encodes a nucleolar protein required for regulated division planes and embryo development in Arabidopsis. Plant Cell 19:2246-2263

Gutmann M (1995) Improved staining procedures for photographic documentation of phenolic deposits in semithin sections of plant tissues. J Microsc 179:277-281

Harada JJ (2001) Role of Arabidopsis LEAFY COTYLEDON genes in seed development. J Plant Physiol 158:405-409

Hobbie L, McGovern M, Hurwitz LR, Pierro A, Yang Liu N, Bandyopadhyay A, Estelle M (2000) The axr6 mutants of Arabidopsis thaliana define a gene involved in auxin response and early development. Development 127:23-32

Jürgens G (2003) Growing up green: cellular basis of plant development. Mech Dev 120:1395-1406

Jürgens G, Torres Ruiz RA, Berleh T (1994) Embryonic pattern formation in flowering plants. Rev Genet 28:351-371

Kandasamy MK, McKinney EC, Deal RB, Meagher RB (2005) Arabidopsis ARP7 is an essential actin-related protein required for normal embryogenesis, plant architecture, and floral organ abscission. Plant Physiol 138:2019-2032

Kwong RW, Bui AQ, Lee H, Kwong LW, Fischer RL, Goldberg RB, Harada JJ (2003) LEAFY COTYLEDON1-LIKE defines a class of regulators essential for embryo development. Plant Cell 15:5-18

Kyjovska Z, Repkova J, Relichova J (2003) New embryo lethal in Arabidopsis thaliana: basic genetic and morphological study. Genetica 119:317-325

Laux T, Jürgens G (1997) Embryogenesis: a new start into life. Plant Cell 9:989-1000

Laux T, Würschum T, Breuniger H (2004) Genetic regulation of embryonic pattern formation. Plant Cell 16:190-202

Li Z, Thomas TL (1998) PEI1, an embryo-specific zinc finger protein gene required for heart-stage embryo formation in Arabidopsis. Plant Cell 10:383-398

Liu CM, Meinke DW (1998) The titan mutants of Arabidopsis are disrupted in mitosis and cell cycle control during seed development. Plant J 16:21-31

Liu CM, Xu ZH, Chua NH (1993) Auxin polar transport is essential for the establishment of bilateral symmetry during early plant embryogenesis. Plant Cell 5:621-630

Liu F, Xu W, Wei Q, Zhang Z, Xing Z, Tan L, Di C, Yao D, Wang C, Tan Y, Yan H, Ling Y, Sun C, Xue Y, Su Z (2010) Gene expression profiles deciphering rice phenotypic variation between Nipponbare (Japonica) and 93-11 (Indica) during oxidative stress. PLos One 5:1-11

Livak KJ, Schmittgen TD (2001) Analysis of relative gene expression data using real-time quantitative PCR and $2^{-\Delta \Delta C T}$ method. Methods 25:402-408

Lotan T, Ohto M, Yee KM, West MAL, Lo R, Kwong RW, Yamagishi K, Fisher RL, Golberg RB, Harada JJ (1998) Arabidopsis LEAFY COTYLEDON1 is sufficient to induce embryo development in vegetative cells. Cell 93:1195-1205

McElver J, Patton D, Rumbaugh M, Liu C, Yang LJ, Meinke D (2000) The TITAN5 gene of Arabidopsis encodes a protein related to the ADP ribosylation factor family of GTP binding proteins. Plant Cell 12:1379-1392

Meinke DW, Sussex IM (1979) Embryo-lethal mutants of Arabidopsis thaliana: a model system for genetic analysis of plant embryo development. Dev Biol 72:50-61

Naway T, Lukowitz W, Bayer M (2008) Talk global, act localpatterning the Arabidopsis embryo. Curr Opin Plant Biol 11:28-33

Patton DA, Schetter AL, Franzmann LH, Nelson K, Ward ER, Meinke DW (1998) An embryo-defective mutant of Arabidopsis disrupted in the final step of biotin synthesis. Plant Physiol 116:935-946

Rademacher EH, Weijers D (2007) Got root? Initiation of the embryonic root meristem. Int J Plant Dev Biol 1:49-59

Ramirez M, Graham MA, Blanco-Lopez L, Silvente S, Medrano-Soto A, Blair MW, Hernandez G, Vance CP, Lara M (2005) Sequencing and analysis of common bean ESTs building a foundation for functional genomics. Genome Anal 137: $1211-1227$

Raz V, Bergervoet JH, Koorneef M (2001) Sequential steps for developmental arrest in Arabidopsis seeds. Development 128: 243-252

Rozen S, Skaletsky HJ (2000) Primer3 on the WWW for general users and for biologist programmers. In: Krawetz S, Misener S (eds) Bioinformatics methods and protocols: methods in molecular biology. Humana Press, Totowa, pp 365-386

Schwartz BW, Yeung EC, Meinke DW (1994) Disruption of morphogenesis and transformation of the suspensor in abnormal suspensor mutants of Arabidopsis. Development 120:3235-3245

Silué S, Lariguet P, Pankhurst C, Jacquemin JM, Broughton WJ, Baudoin JP (2006) Screening Phaseolus vulgaris L. EMS 
mutants to isolate plants which failed in seed development. Annu Rep Bean Improv Coop 49:149-150

Sollner R, Glasser G, Wanner G, Somerville CR, Jürgens G, Assaad FF (2002) Cytokenesis-defective mutants of Arabidopsis. Plant Physiol 129:678-690

Steinborn K, Maulbetsch C, Priester B, Trautmann S, Pacher T, Geiges B, Küttner F, Lepiniec L, Stierhof YD, Schwarz H, Jürgens G, Mayer U (2002) The Arabidopsis PILZ group genes encode tubulin-folding cofactor orthologs required for cell division but not cell growth. Gene Dev 16:959-971

Tsuwamato R, Takhata Y (2008) Identification of genes specifically expressed in androgenesis-derived embryo in rapeseed (Brassica napus L.). Breed Sci 58:251-259

Tzafrir I, McElver JA, Liu C, Yang LJ, Wu JQ, Martinez A, Patton D, Meinke D (2002) Diversity of TITAN functions in Arabidopsis seed development. Plant Physiol 128:38-51

Tzafrir I, Dickerman A, Brazhink O, Nguyen Q, McElver J, Frye C, Patton D, Meinke D (2003) The Arabidopsis seed genes project. Nucleic Acids 31:90-93

Tzafrir I, Pena-Muralla R, Dickerman A, Berg M, Rogers R, Hutchens S, Sweeney TC, McElver J, Aux G, Patton D, Meike D (2004) Identification of genes required for embryo development in Arabidopsis. Plant Physiol 135:1206-1220

Vernon DM, Hannon MJ, Le M, Forsthoefel NR (2001) An expanded role for the TWN1 gene in embryogenesis: defects in cotyledon pattern and morphology in the TWN1 mutant of Arabidopsis (Brassicaceae). Am J Bot 88:570-582
Vidaure DP, Ploense S, Krogan NT, Berleth T (2007) AMP1 and MP antagonistically regulate embryo and meristem development in Arabidopsis. Development 134:2561-2567

Weijers D, Franke-van Dijk M, Vencken RJ, Quint A, Hooykaas P, Offringa R (2001) An Arabidopsis Minute-like phenotype caused by a semi-dominant mutation in a RIBOSOMAL PROTEIN S5 gene. Development 128:4289-4299

Wu X, Li F, Zhang C, Liu C, Zhang X (2009) Differential gene expression of cotton cultivar CCRI24 during somatic embryogenesis. J Plant Physiol 166:1275-1283

Yamagishi K, Nagata N, Yee KM, Braybrook SA, Pelletier J, Fujioka S, Yoshida S, Fischer RL, Goldberg RB, Harada JJ (2005) TANMEI/EMB 2757 encodes a WD repeat protein required for embryo development in Arabidopsis. Plant Physiol 139:163-173

Yeung EC, Meinke DW (1993) Embryogenesis in angiosperms: development of the suspensor. Plant Cell 5:1371-1381

Yeung EC, Sussex IM (1979) Embryology of Phaseolus coccineus: the suspensor and the growth of the embryo-proper in vitro. Z Planzenphysiol 91:423-433

Zakizadeh H, Stummann BM, Lütken H, Müller R (2010) Isolation and characterization of four somatic embryogenesis receptor-like kinase (RhSERK) genes from miniature potted rose (Rosa hybrid cv. Linda). Plant Cell Tissue Organ Cult 101:331-338

Zhang JZ, Somerville CR (1997) Suspensor-derived polyembryony caused by altered expression of valyl-tRNA synthetase in the twn2 mutant of Arabidopsis. Dev Biol 94:7349-7355 